\title{
Gesto decolonial como pedagogia: práticas teatrais no Brasil e no Peru ${ }^{1}$
}

Decolonial gesture as pedagogical method: theatrical practices in Brazil and Peru

Gilberto Icle ${ }^{2}$

Marta Haas ${ }^{3}$ 


\section{Resumo}

Este artigo procura circunscrever a pedagogia a partir da noção de gesto decolonial. Para tanto, toma-se a prática artístico-pedagógica do Yuyachkani (Peru) e do Ói Nóis Aqui Traveiz (Brasil) como forma de resistência e elemento por intermédio do qual rompe-se a colonialidade dos saberes e das relações de poder. A partir dos conceitos de diferença colonial, colonialidade e pensamento liminar delineados por Walter Mignolo, demonstra-se como esse gesto de resistência à colonialidade participa na constituição de sujeitos e subjetividades autônomas. Problematiza-se o trabalho desses grupos latino-americanos caracterizando suas práticas como gestos e pedagogias do teatro decoloniais.

Palavras-chave: Pedagogia; decolonial; resistência; teatro de grupo; teatro latino-americano

\section{Abstract}

This article seeks to circumscribe pedagogy through the notion of decolonial gesture. For that, the artistic-pedagogical practices of Yuyachkani (Peru) and Ói Nóis Aqui Traveiz (Brazil) are taken up as forms of resistance and elements through which to break the coloniality of power relations and knowledge. Applying Walter Mignolo's concepts of colonial difference, coloniality and liminal thinking, this article demonstrates how this gesture of resistance against coloniality helps constitute autonomous subjects and subjectivities. The work of these two Latin American groups is problematised, characterising their practices as decolonial theatrical gestures and pedagogies.

Keywords: Pedagogy; decolonial; resistance; collective theatre; latin american theatre

\footnotetext{
1 O presente trabalho foi realizado com apoio da Coordenação de Aperfeiçoamento de Pessoal de Nível Superior - Brasil (CAPES) - Código de Financiamento 001 e com Bolsa de Produtividade do CNPq.

2 Professor permanente no Programa de Pós-Graduação em Educação da Universidade Federal do Rio Grande do Sul (PPGEDU-UFRGS) e no Programa de PósGraduação em Artes Cênicas da Universidade de Brasília (PPG-CEN UnB). Bolsista de Produtividade 1-D do CNPq - gilbertoicle@gmail.com

3 Doutoranda no Programa de Pós-Graduação em Educação da Universidade Federal do Rio Grande do Sul (PPGEDU-UFGRS). - martitahaas@gmail.com
} 
Catherine Walsh, que se identifica como uma militante intelectual, ativista e pedagoga, envolveu-se em diversos processos e lutas por justiça e transformação social na América Latina. Ao narrar algumas experiências pedagógicas que teve nesses processos, ela afirma que

lo decolonial no viene desde arriba sino desde abajo, desde los márgenes y de los bordes, de la gente, las comunidades, movimientos, colectivos que retan, interrumpen y transgreden las matrices del poder colonial en sus prácticas de ser, actuación, existencia, creación y pensamiento. Lo decolonial, en este sentido, no es un estado fijo, un estatus o condición; tampoco denota un punto de llegada. Es un proceso dinámico siempre en proceso de hacerse y re-hacerse dada la permanencia y capacidad de reconfiguración de la colonialidad del poder. Es un proceso de lucha, no solo contra sino más importante aún, para- para la posibilidad de un otro-modo o modo-otro de vida. Un proceso que engendra, invita a la alianza, conectividad, articulación e interrelación, y lucha por la invención, creación e intervención, por sentimientos, significados y horizontes radicalmente distintos". (Walsh, 2014, n.p.)

O decolonial, portanto, é um processo de luta tanto contra uma matriz colonial e seus preceitos universalizantes, homogeneizadores, hierarquizantes e eurocêntricos, quanto por outros conhecimentos e outras formas possíveis de existência, sempre em inter-relação e articulação com o outro. Nesse sentido, Walter Mignolo (2014), pesquisador que possui uma vasta produção em torno da questão colonial e geopolítica do conhecimento, busca o significado do que seria um gesto decolonial. Se entendermos a definição de gesto como um movimento do corpo ou dos membros que expressa ou enfatiza uma ideia, sentimento ou atitude, nós chegamos próximos do significado de gesto decolonial: um movimento do corpo que carrega um sentimento e/ou uma intenção decolonial; um movimento que aponta para algo já constituído como um gesto colonial, contrapondo-se a ele. O gesto decolonial, portanto, está relacionado com pensamentos e práticas que rompem com a colonialidade do saber e do poder, contribuindo para a emergência de falas e saberes locais: indígenas, mestiços, femininos, africanos, campesinos etc. A opção decolonial põe em xeque as ideologias totalitárias da modernidade, por meio de uma lógica anti-universalista e anti-homogeneizadora, que afirma outro-modo ou modo-outro de vida, sempre em processo de fazer-se e refazer-se. Com efeito, ainda segundo Mignolo,

gestos decoloniais seriam quaisquer e todos os gestos que direta ou indiretamente se engajam na desobediência dos ditames da matriz colonial e contribuem para a construção da espécie humana no planeta em harmonia com a vida no/do planeta, da qual a espécie humana é apenas uma ínfima parte e da qual depende. E isso contribuiu para a re-emergência, res-surgência e re-existência planetária de pessoas cujos valores, modos de ser, línguas, pensamentos e histórias foram degradados para serem dominados. $(2014, \text { n.p. })^{4}$

Dessa forma, tomamos aqui a noção de gesto decolonial para compreendermos as pedagogias de dois grupos de teatro - o Grupo Cultural Yuyachkani (Peru)

\footnotetext{
4 "decolonial gestures would be any and every gesture that directly or indirectly engages in disobeying the dictates of the colonial matrix and contributes to building of the human species on the planet in harmony with the life in/of the planet of which the human species is only a minimal part and of which it depends. And that would contribute to planetary re-emergence, re-surgence, and re-existence of people whose values, ways of being, languages, thoughts, and stories were degraded in order to be dominated". (Todas as traduções colocadas neste artigo são de nossa autoria).
} 
e a Tribo de Atuadores Ói Nóis Aqui Traveiz (Brasil) - na sua produção subjetiva, na sua possibilidade de subjetivação. Assim, este artigo propõe pensar essas pedagogias como possibilidade de gesto decolonial, ou ainda, pensar o gesto decolonial como pedagogia por intermédio da qual se produzem no interior das relações sociais outros modos de vida, outras possibilidades de práticas.

Para tanto, escolhemos descrever e analisar algumas práticas artístico-pedagógicas no Brasil e no Peru que, segundo nosso olhar, podem dar conta do objetivo deste trabalho: descrever gestos decoloniais que configurem pedagogias decolonizadas. Esse gesto decolonial, uma vez que rompe com a colonialidade dos saberes e das relações de poder, participa na constituição de sujeitos e subjetividades autônomas, que escapam ao normativo e ao hegemônico e produzem saberes e valores próprios 5 .

É importante ressaltar que esses grupos não desvinculam o processo pedagógico do processo de criação artística ${ }^{6}$. O processo de formação do ator se dá pela própria prática, aliada à reflexão acerca do fazer teatral e dos temas sociais, históricos e políticos relacionados às montagens criadas. Estende-se, inclusive, a projetos que visam a não só formar atores, mas também cidadãos responsáveis. Por isso, falamos em ações artístico-pedagógicas. Não só as próprias oficinas, destinadas ao aprendizado teatral e ao desenvolvimento do ator, são atividades formativas, mas também as ações no campo da criação e do compartilhamento.

Os processos de criação e compartilhamento formam não só os próprios atores, mas pretendem estabelecer relações pedagógicas também com o público a que se destina. Nesse sentido, assistir a um espetáculo também pode se tornar uma instância de aprendizagem, que alie divertimento e reflexão, que contribua para o conhecimento dos homens sobre si e para o aprimoramento de sua condição. Os coletivos buscam fazer um teatro que seja uma instância de aprendizado mútuo entre artistas e seu público. Essa característica, própria dos grupos desde seu surgimento, foi ganhando contornos mais delineados ao longo do tempo, na medida em que o diálogo com seu público foi se aprofundando.

Para analisar esses processos pedagógicos, nosso ponto de partida foi pensar que práticas de resistência emergiram e emergem em suas ações artístico-pedagógicas. Não buscamos uma origem para determinadas escolhas e ações, mas procuramos entende-las no contexto de suas emergências. Desenvolvemos o modo como a noção de resistência participa na constituição de sujeitos e subjetividades, uma vez que produz saberes que de alguma forma conduzem e ensinam modos de ser e estar na cultura e na época em que se vive. Com base no percurso histórico dos coletivos, observamos que a resistência necessária no surgimento dos grupos, na década de 1970, em pleno período de ditaduras e governos militares, não é a mesma a partir do momento de transição democrática, em que o inimigo contra o qual se luta torna-se difuso e descentralizado.

50 uso que fazemos aqui da noção de decolonialidade ou decolonial não esgota, por certo, as possibilidades que tal ferramenta teórico-metodológica possui no campo das artes da cena. Não seria possível para as dimensões deste artigo espraiar-se para outros domínios. Sobre as possibilidades epistemológicas do termo decolonial no campo das artes da cena veja, por exemplo, o trabalho de Bisiaux (2018).

6 Essa postura epistemológica pode ser bem compreendida em outros trabalhos de nossa autoria, ver especialmente Icle (2011). 
Como resistir nessas condições e contra quem? Nesse momento de fragmentação e descentralização das relações de poder, foi preciso reinventar formas de resistência amparadas por subjetividades autônomas e saberes locais. A ideia de um sujeito plenamente consciente de seu papel, que luta contra um único inimigo e é capaz de desvelar verdades imutáveis, dá lugar a um sujeito que deve ser constantemente reinventado. Isso não significa que não se saiba de que lado se está, pois os grupos seguem firmes na ideia de que o teatro pode contribuir para a transformação social, pode contribuir na busca por justiça e por um mundo mais solidário. Porém, as formas de subjetivação são outras.

O próximo passo consistiu em analisar algumas formas de resistência identificadas nos dois coletivos. Observamos que as ações artístico-pedagógicas dos grupos constituem um gesto decolonial que possibilitam práticas pedagógicas decoloniais. Essas práticas evocam a independência e a potência do local, do emergente e do marginalizado frente aos imperativos universalizantes e hierárquicos.

Escolhemos, entrementes, a arte, o teatro, as práticas performáticas em função de sua potência para refletirmos de modo a nos distanciarmos das formas pedagógicas mais conhecidas e podermos reconhecer no interior dos gestos decoloniais a forma por intermédio da qual se plasmam diferentes possibilidades pedagógicas.

\section{Pedagogias decoloniais no teatro de grupo latino-americano}

A ideia central que se quer demonstrar aqui é, principalmente, esse gesto decolonial como elemento por intermédio do qual as pedagogias tomam forma como resistência aos modelos hegemônicos. Tais gestos, nos casos estudados, desenham pedagogias decoloniais na medida em que se relacionam não com a elite burguesa acostumada a frequentar o teatro, mas com comunidades diversas, principalmente distantes dos bens culturais reconhecidos como centrais na cultura.

Cabe ressaltar que ambos os coletivos foram formados por jovens estudantes interessados em fazer um teatro comprometido eticamente com a sociedade da qual faziam parte. Por isso, desde o princípio, os temas abordados em suas pesquisas possuem cunho social e as camadas da população normalmente marginalizadas passam a ganhar voz. Muito cedo sentiram necessidade de realizar oficinas teatrais em comunidades fora dos centros urbanos, para que o teatro contribuísse de alguma forma na busca de uma vida melhor para toda a população. Ambos os grupos, também, estavam comprometidos em fazer um teatro de ruptura com os parâmetros tradicionais de então.

Esses grupos são herdeiros de uma tradição teatral de esquerda dos anos 1950 e 1960, porém são confrontados com urgências próprias de um período de transição para a democracia. Na busca por novas formas de articular o político e o social, a ação pedagógica foi fundamental para a própria constituição do grupo. As pedagogias dos grupos estudados, portanto, circunscrevem gestos (não apenas em seus trabalhos artísticos, em espetáculos, mas, sobretudo, em ações pedagógicas) como forma de resistir e, ao mesmo tempo, como modos de subjetivação decoloniais, reconhecendo saberes periféricos. 
O Grupo Cultural Yuyachkani e a Tribo de Atuadores Ói Nóis Aqui Traveiz desenham pedagogias culturais e decoloniais na própria escolha do nome e dos logotipos. Yuyachkani é uma palavra em quéchua que significa "estou pensando, estou recordando". A escolha de um nome em quéchua, uma das línguas dos povos originários da região dos Andes, já denota a proximidade com a tradição cultural peruana e andina. A referência do nome mostra a importância dada à pesquisa da memória, individual e coletiva, particularmente em relação a questões sociais sobre violência e repressão no Peru. O nome também evoca a importância dada pelos povos originários à oralidade como forma de contar e transmitir histórias, provocando um retorno ao passado para melhor compreender o presente.

O logotipo do Yuyachkani mostra um zorro, que é uma espécie de raposa típica dos Andes. Segundo Diana Taylor (2013), a lenda sobre os zorros - que já era considerada antiga quando foi escrita pela primeira vez no século XVI - foi reinterpretada no famoso livro do sociólogo peruano José Maria Arguedas intitulado El zorro de arriba y el zorro de abajo (1968). Esse mesmo romance inspirou a criação de dois espetáculos do grupo: Encuentro de zorros (1985) e Cartas de Chimbote (2015). Os zorros, como símbolo de mudança, aparecem de forma cíclica em momentos de extrema crise social. Já na sua primeira aparição, há aproximadamente dois mil e quinhentos anos, eles se encontraram para censurar publicamente a injustiça social. Segundo a lenda, os zorros têm o desafio de devorar o mundo e criar um novo. Para Taylor (2013, p. 279), o Yuyachkani "usa o mito para novamente refletir sobre os cismas geográficos, étnicos e linguísticos do Peru". Enquanto o zorro de cima representa a população serrana da cordilheira andina, o zorro de baixo representa a população da região costeira de Lima. No espetáculo de 1985, o encontro dos zorros dramatiza o choque social e intercultural entre um homem andino que migra para a cidade e um homem urbano que ali sobrevive, excluído e marginalizado. O zorro usado no logotipo, portanto, evoca o imaginário andino e traz a necessidade de transformação em momentos de crise e injustiça social.

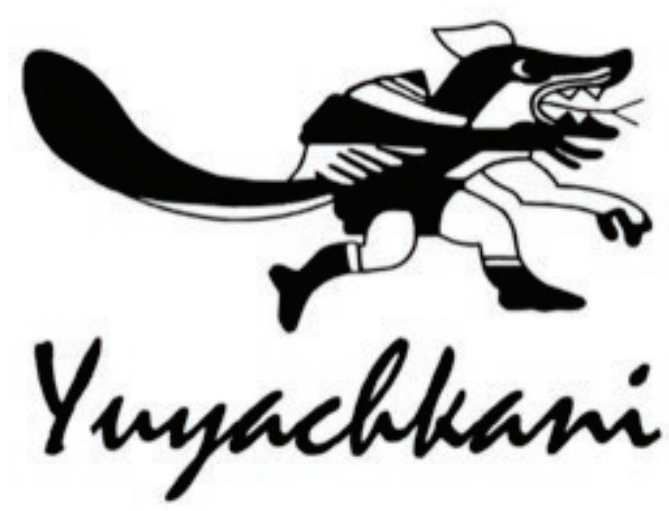

Figura 1: Logotipo do Grupo Cultural Yuyachkani. Fonte: $<$ https://www.facebook.com/grupoyuyachkani/>

O nome Tribo de Atuadores Ói Nóis Aqui Traveiz, por sua vez, traz consigo várias alusões. Ói Nóis Aqui Traveiz faz referência a uma música que ficou conhecida por meio do grupo musical Demônios da Garoa. Em português iletrado, a expressão pos- 
sui um caráter popular que subverte os padrões gramaticais e reivindica persistência, resistência e comunhão. O termo atuador, por sua vez, remete à concepção de teatro num sentido mais amplo, em que arte e vida se fundem, numa relação mais aberta e direta com o público. Não se atua apenas em cena, mas na vida, também por meio de uma militância política e social, por isso fala-se que o termo remonta a uma mistura de artista com ativista. A ideia de tribo sugere, segundo Paulo Flores (apud ALENCAR, 1997, p. 71), "um tipo de sociedade que emerge baseada na comunidade e camaradagem, nas relações pessoais diretas e na responsabilidade individual". Por sua vez, o nome do espaço do grupo, a Terreira, vem de terreiro, o lugar no qual são celebrados os cultos afro-brasileiros, um espaço ritual, porém feminino, revelando a potência de um terreno fértil para a criação.

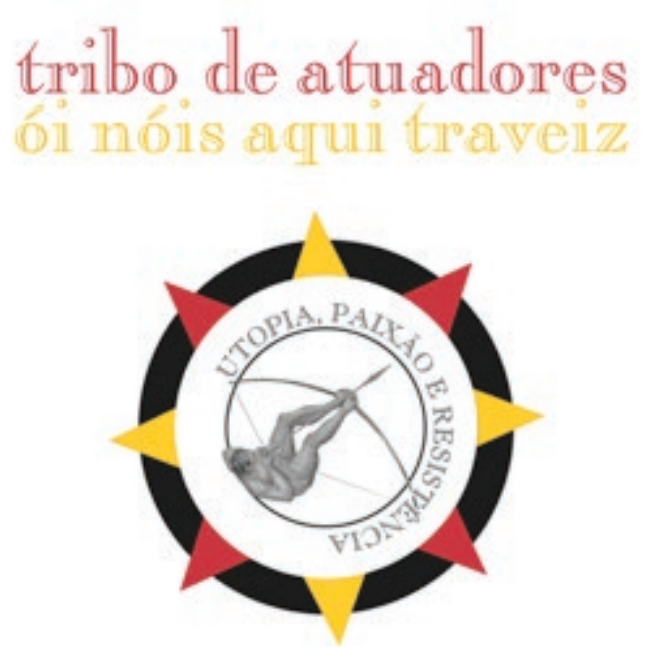

Figura 2: Logotipo da Tribo de Atuadores Ói Nóis Aqui Traveiz. Fonte: Arquivo da Tribo

O logotipo da Tribo de Atuadores Ói Nóis Aqui Traveiz apresenta a imagem de um indígena nu deitado de costas, que maneja um arco e flecha com as mãos e os pés. Essa imagem é uma versão de uma famosa pintura de Jean-Baptiste Debret. $O$ indígena, que possui uma grande habilidade no manejo do arco e flecha, é rodeado pelas palavras utopia, paixão e resistência. A imagem evoca a prontidão para a resistência, necessária para um grupo teatral que surgiu em pleno regime militar e teve de inventar diversas maneiras de se sustentar de forma independente, sem ceder aos padrões éticos e estéticos do mercado. A utopia aparece como aquilo que rege as ações do grupo em busca de um mundo mais solidário. E a paixão como aquilo que move o desejo para lutar por justiça e transformação social.

O fazer artístico desses coletivos também denota um gesto decolonial. Ao montar espetáculos e realizar atividades pedagógicas e ativistas que possibilitam que vozes marginalizadas sejam ouvidas, os grupos comprometem-se em desafiar o status quo e buscar novas possibilidades de existência que não sejam regidas pela lógica colonialista, que subalterniza determinadas histórias e saberes. 


\section{Colonialidade, colonialismo, descolonialização}

É importante ressaltar que o colonialismo europeu, seja na América Latina ou em outras colônias situadas na Ásia ou na África, deixou como legado não apenas a desigualdade e injustiça social. A colonialidade do saber e do poder deixou como legado um eurocentrismo intelectual que nos impede de compreender o mundo a partir do nosso próprio mundo e de nossas próprias epistemes. Segundo Walter Mignolo (2003, p. 41), "da perspectiva epistemológica, o saber e as histórias locais europeias foram vistos como projetos globais", impondo-se um imaginário dominante que sufocou outros saberes locais e deu origem ao chamado sistema-mundo moderno.

Para fazer sua crítica ao eurocentrismo, Mignolo utiliza o conceito de diferença colonial, entendida como um choque de mundos: uma irredutível dissonância de percepções que acontece quando diferentes culturas entram em contato no contexto da dominação colonial. Dessa forma, a diferença colonial é o espaço no qual as histórias locais que implementam projetos globais encontram outras histórias locais, é "o espaço onde os projetos globais são obrigados a adaptar-se, integrar-se ou onde são adotados, rejeitados ou ignorados" (Mignolo, 2003, p. 10).

Para Mignolo, apesar de ser dada como natural, como parte de uma ordem universal, a transformação da diferença cultural em valores e hierarquias não é uma distinção ontológica, mas é fabricada por determinadas regiões do mundo e determinadas pessoas. Aqueles que classificam controlam o conhecimento. A diferença colonial torna-se uma estratégia que permite transformar diferenças em valores e hierarquias, e que é utilizada há séculos para rebaixar saberes, culturas, povos e regiões do mundo. Essa classificação e hierarquização é a base epistemológica para a construção da colonialidade do saber e do poder.

Assim, na medida em que o continente americano empobreceu, sob o aspecto material, a injeção de riqueza material na Europa, advinda da exploração colonial, inseriu o continente europeu no sistema-mundo moderno. O conceito de sistema-mundo moderno foi aprofundado por diversos intelectuais sul-americanos, como o economista peruano Aníbal Quijano. Para ele, a modernidade europeia está enraizada na construção do sistema colonial de exploração. Portanto, "as Américas não foram incorporadas a uma economia mundial capitalista já existente. Não poderia ter havido uma economia capitalista mundial sem as Américas" (Quijano apud Mignolo, 2003, p. 84).

Aníbal Quijano afirma que o próprio capitalismo impõe um padrão de poder baseado nas formas de dominação colonial. Para elucidar esse processo, ele cunhou o conceito de colonialidade como algo que transcende as particularidades do colonialismo histórico e que não desaparece com a independência ou descolonização. Essa formulação é uma tentativa de explicar a modernidade como um processo intrinsecamente vinculado à experiência colonial (Mignolo, 2003). A distinção entre colonialidade e colonialismo permite explicar a continuidade das formas coloniais de dominação, mesmo após o fim das administrações coloniais, além de demonstrar que essas estruturas de poder e subordinação passaram a ser reproduzidas pelos mecanismos do sistema-mundo colonial/moderno. Isso mostra porque a extinção do 
colonialismo histórico-político nas Américas não foi condição necessária e suficiente para a emancipação política, econômica e cultural desses países ditos periféricos.

A colonialidade do saber e do poder refere-se a todos os mecanismos de controle do conhecimento, subjetividade, exploração do trabalho e hierarquização do mundo que formam a base do sistema-mundo sob o domínio europeu. Com a introdução do conceito de raça, a colonialidade favoreceu tanto a constituição quanto a perpetuação da existência de sujeitos e saberes subalternizados.

Para Mignolo há três caminhos possíveis de posicionamento para quem habita o lado da colonialidade: "tentamos nos assimilar, e boa sorte na assimilação; nos adaptamos o melhor que podemos, pois temos que viver; ou, o terceiro, nos adaptamos e começamos a construir projetos que apontam para outras formas de vida" (2013, p. 3). O terceiro caminho aponta para uma consciência de fronteira, transformada em pensamento liminar ${ }^{7}$, que tem como principal característica a possibilidade de teorizar a partir da margem - daí o sentido de liminar - e de uma perspectiva subalterna. Recupera a simultaneidade de distintos lugares, pensamentos e lógicas na conformação de nosso mundo: é preciso abrir espaço para que múltiplas epistemes dialoguem. Segundo o autor, o pensamento liminar empreende um diálogo, por meio da noção de diferença cultural, entre a noção de insurreição dos saberes subjugados de Michel Foucault e a noção de saberes subalternos de Darcy Ribeiro.

Entre 1975 e 1976, Michel Foucault ministrou um curso no Collège de France sobre a genealogia do racismo, conhecido como Em defesa da sociedade (1999). Em sua primeira aula, Foucault introduziu a expressão insurreição dos saberes subjugados para descrever uma mudança epistemológica que ele vinha percebendo. Nos últimos quinze anos, anunciou ele, a mobilização social tomou a forma de críticas sociais autônomas, que foram legitimadas não pela adoção de teorias envolventes e globais, mas pela crítica local. A chamada insurreição dos saberes subjugados inclui tanto saberes altos e eruditos - "conteúdos históricos que foram sepultados, mascarados em coerências funcionais ou em sistematizações formais" (Foucault, 1999, p. 11) - quanto saberes baixos, populares, locais e particulares (do delinquente, do enfermo, do paciente psiquiátrico), que "estavam desqualificados como saberes não conceituais, como saberes insuficientemente elaborados" (p. 12). Essa insurreição serviu para despertar "os saberes históricos das lutas. [...] a memória dos combates, aquela, precisamente, que até então tinha sido mantida sob tutela" (p. 13).

Nesse campo de redescoberta de lutas e memória de combates, a genealogia opera acoplando ambos os níveis de saberes, erudito e local. Esse acoplamento é

\footnotetext{
7 O termo liminar, na antropologia, foi inicialmente explorado por Arnold Van Gennep para demarcar as situações de margem ou límen que aparecem nos rituais de passagem, separados da vida cotidiana. A liminaridade emerge como uma antiestrutura que põe em crise os sistemas e hierarquias sociais. A partir do diálogo e colaboração entre o antropólogo Victor Turner e o pesquisador e encenador Richard Schechner, foram exploradas as similaridades e as diferenças entre o arranjo cultural e performativo do drama social e do drama estético. No centro dessa relação entre o drama social e o drama estético estão os conceitos de "performance" e "drama". Podemos observar uma estrutura dramática dentro dos dramas sociais, de forma análoga às estruturas cênicas, que expressam o potencial teatral da vida social. Turner aponta que no drama social também emerge a liminaridade, não na dimensão sagrada dos rituais de passagem pesquisados por Arnold Van Gennep, mas na própria sociedade. De acordo com Schechner, "Turner percebeu que existia uma diferença entre o que acontecia em culturas tradicionais e culturas modernas. Com a industrialização e a divisão do trabalho, muitas das funções do ritual são retomadas pelas artes, entretenimento e recreação. Turner usou o termo liminoide para descrever tipos de ações simbólicas que ocorreram em atividades de lazer, similares ao ritual" (Schechner, 2012, p. 66). Victor Turner apontou quatro fases que operavam no drama social: 1) fenda; 2) crise; 3) ação reparadora; 4) reintegração. Na segunda fase emerge a liminaridade. No âmbito dos Estudos da Performance, assim como na proposta decolonial, podemos demarcar situações liminares que desafiam o status quo, remodelando estruturas sociais e buscando novas possibilidades de organização.
} 
possível desde que seja "revogada a tirania dos discursos englobadores, com sua hierarquia e com todos os privilégios das vanguardas teóricas" (Foucault, 1999, p. 13). Possui um objetivo político: permite-nos "a constituição de um saber histórico das lutas e a atualização desse saber nas táticas atuais" (1999, p. 13). A genealogia constitui-se como uma anti-ciência, não no sentido de que deve render-se à ignorância, mas como uma insurreição contra os efeitos centralizadores de poder que são vinculados às instituições e ao funcionamento do discurso científico em nossa sociedade, contra sua dominação sobre outras formas de conhecimento. A genealogia trava um combate contra os efeitos de poder próprios de um discurso considerado científico. Trata-se de "uma espécie de empreendimento para dessujeitar os saberes históricos e torná-los livres, isto é, capazes de oposição e de luta contra a coerção de um discurso teórico, formal e científico" (1999, p. 15).

É importante ressaltar que a genealogia não busca uma origem das coisas, mas as condições para a sua emergência. A análise história tradicional, com seus projetos globais, constrói uma explicação totalizante, ordenando os fatos numa temporalidade sequencial, em busca do contínuo e teleológico. A genealogia, em contrapartida, privilegia a descontinuidade e a pluralidade dos acontecimentos em sua dispersão. Trata o acontecimento histórico no jogo de sua instância, renunciando à crença de um acontecimento verdadeiro e de um progresso contínuo ligado a uma evolução do pensamento. Se não há uma origem e um telos da história, o que existe são relações de força, lutas, combates, jogo de acasos. A investigação genealógica, portanto, permite questionar a maneira pela qual certas verdades e seus efeitos práticos vieram a se estabelecer no presente. Se essas verdades são contingentes e mutáveis, existe a possibilidade de questioná-las e transgredi-las.

Ao considerar a noção de saberes subjugados de Foucault e sua capacidade transgressora, uma vez que questiona determinadas verdades, Mignolo tem a intenção de transportá-los "até os limites da diferença colonial, onde os saberes subjugados se tornam subalternos na estrutura da colonialidade do poder" (Mignolo, 2003, p. 45). Se concebermos os saberes subjugados em pé de igualdade com o eurocentrismo como imaginário dominante, "a face visível do edifício do mundo moderno" (p. 45), os saberes subalternos são seu lado sombrio, o lado colonial da modernidade. Mignolo traz como exemplo a diferença colonial que foi evidenciada por Darcy Ribeiro, no fim dos anos 1960, entre os antropólogos do primeiro mundo estudando o terceiro mundo e os antropologianos ${ }^{8}$ do terceiro mundo refletindo sobre suas próprias condições geográficas, históricas e coloniais. Mignolo cita Darcy Ribeiro (2003, p. 45-46):

os colonizados, privados de sua riqueza e do fruto de seu trabalho sob a dominação colonial, sofreram, ademais, a degradação de assumir como sua a imagem que era um simples reflexo da cosmovisão europeia, que considerava os povos coloniais racialmente inferiores porque eram negros, ameríndios ou mestizos. Mesmo as camadas mais inteligentes dos povos não-europeus acostumaram-se a enxergar-se e a suas comunidades como uma infra-humanidade, cujo destino era ocupar uma posição subalterna pelo simples fato de que a sua era inferior à da população europeia.

8 Autodenominação de Darcy Ribeiro em substituição a de antropólogo, para expressar sua condição de antropólogo consciente da sua subalternidade na geopolítica do conhecimento.

Gilberto Icle, 
Os saberes subalternos e o pensamento liminar, portanto, desafiam e transgridem os postulados da colonialidade. Mignolo ressalta, em seu projeto de descolonização do conhecimento, que os saberes subalternos geram narrativas que rompem radicalmente com projetos globais. Essas narrativas não seriam (ou, pelo menos, não apenas) "nem narrativas revisionistas, nem narrativas que pretendem contar uma verdade diferente, mas, sim, narrativas acionadas pela busca de uma lógica diferente" (Mignolo, 2003, p. 47). Essa lógica diferente implica em resgatar o acúmulo de saberes que desde a ocupação das Américas foram silenciados pelos colonizadores.

\section{Os saberes locais como pedagogias decoloniais}

Os grupos Yuyachkani e Ói Nóis Aqui Traveiz sentiram a necessidade de criar, ao longo de sua trajetória, espetáculos que refletem sobre a diversidade cultural de seus países. Essa prática está alinhada com a busca daquilo que Walter Mignolo chamou de uma lógica diferente, que resgata saberes locais silenciados por projetos globais e produz novos saberes e narrativas. O Yuyachkani, por exemplo, criou espetáculos sobre a população peruana mais atingida pelas atrocidades do chamado conflito armado interno (1980-2000), fruto da disputa entre os militares e os senderistas. Alguns desses espetáculos, inclusive, baseiam-se em documentos e relatos reais de mulheres e homens campesinos sobre a violência sofrida. Nessas obras, o Yuyachkani também utiliza as tradições, ritos, danças, festas e costumes do povo andino, aproximando-se de tradições pré-hispânicas.

Se no seu surgimento os Yuyas se propunham a esclarecer a população peruana explorada, com o tempo perceberam que era preciso levar em conta a tradição cultural dessa população e era preciso, antes de tudo, conhecer essa tradição. Isso deu início ao estudo contínuo sobre as práticas performáticas indígenas e mestiças, que incluem canto, uso de instrumentos musicais, dança, máscara e outras formas de expressão. Segundo Diana Taylor, "seu teatro passou a não ser 'sobre eles', mas sobre uma reflexão mais complexa a respeito da heterogeneidade étnica e cultural do Peru" (2013, p. 276).

Essa reflexão mais profunda sobre a complexidade cultural, temporal, geográfica, histórica e étnica do Peru levou à criação do espetáculo Los músicos ambulantes (1983). A obra é inspirada no conto popular Os músicos de Bremen e na versão musical Os Saltimbancos de Chico Buarque, utilizando máscaras, música, dança e cenas cômicas. Fala sobre a injustiça social e a importância de se trabalhar coletivamente. Quatro personagens completamente distintos - a galinha, o cachorro, o gato e o burro - compreendem que, apesar de suas diferenças e incompatibilidades, juntos eles estarão melhores do que separados. Diana Taylor afirma que, sob um ponto de vista, o espetáculo aponta para uma importante reflexão sobre a composição racial do Peru.

O cachorro representa o crioulo de Lima, dos bairros altos ou de setores pobres da cidade. A galinha faz as vezes das populações afro-peruanas. O gato vem da selva, o vale amazônico peruano, enquanto o burro representa o cholo serrano, o mestiço dos Andes. Essas figuras, todas elas de alguma forma perseguidas, vencidas e exploradas, reúnem-se para se rebelarem contra o patrón de modo exuberante. A negociação entre eles exige que se conheçam melhor, que reconheçam os pontos fortes de cada um e o que contribui para o grupo. (Taylor, 2013, p. 278) 
Ao valer-se de personagens da tradição cultural peruana para contar as histórias omitidas sobre violência, tortura, morte e desaparecimento, o grupo transforma esses personagens populares em denunciantes das atrocidades cometidas por militares e senderistas, aproximando-se da própria população vítima dessa violência. A obra Adiós Ayacucho (1990), um solo do ator Augusto Casafranca, é inspirada num texto de Julio Ortega. Mostra a história de Alfonso Canepa, um dirigente camponês torturado, massacrado, morto, mutilado e enterrado de modo incompleto numa vala comum. Ao entrar no corpo de uma espécie de dançante - o Qolla, personagem mascarado típico da dança tradicional Capac Qolla de Cusco - viaja de Ayacucho a Lima com o objetivo de recuperar as partes desaparecidas de seu corpo, que seus assassinos devem ter levado para a capital, para que possa ser enterrado e descansar em paz.

Também é o caso de Rosa Cuchillo (2002), solo da atriz Ana Correa a partir do texto homônimo de Oscar Colchado Lucio. A ação cênica irrompe o cotidiano da população e surpreende pelo diálogo da teatralidade com o ritual. É um rito de purificação, limpeza e florescimento aos modos da tradição de alguns povos andinos do Peru. Rosa Cuchillo é a mãe que busca seu filho morto e desaparecido para além da morte, percorrendo os outros mundos (mundo de abajo e mundo de arriba). Seu retorno a esse mundo busca harmonizar a vida e romper com o medo e o silêncio, para que se comece a sanar o esquecimento.

Ambas as obras, Adiós Ayacucho e Rosa Cuchillo, acompanharam as audiências e o informe final da Comisión de la Verdad y Reconciliación (CVR) ${ }^{9}$, que surgiu em 2001, depois de uma grande mobilização da sociedade civil, com o objetivo de pensar as consequências do conflito armado interno. A CVR ficou encarregada de investigar os crimes e violações dos direitos humanos cometidos entre 1980 e 2000 . Os testemunhos dos afetados pela violência diante da comissão marcaram o momento em que o país começou a tomar consciência de todo o horror perpetrado.

O Ói Nóis Aqui Traveiz, por sua vez, também realizou diversas montagens que retratam a história dos excluídos e marginalizados. A necessidade de produzir outras narrativas acerca da história do Brasil - a partir de visões e saberes subalternos, que possam ser compartilhados de forma democrática e descentralizada - levou o grupo a pesquisar uma linguagem própria e contundente para o teatro de rua. $A$ ação de levar o teatro para as ruas e praças de bairros de periferia, assim como para assentamentos rurais, por meio do projeto Caminho para um teatro popular, realizado desde 1988, deixa claro o intuito de democratizar e descentralizar saberes.

A ação cênica, que é considerada o primeiro espetáculo de teatro de rua do Ói Nóis, intitulada Teon - morte em tupi-guarani (1984), era apresentada como um rito, "uma prece aos milhões de índios mortos em toda América" (Alencar, 1997, p. 100). Uma sequência de quadros - vida comunitária, cultura, religiosidade, contato com o homem branco, doença, escravidão e aniquilamento da cultura indígena - mostrava o processo de colonização dos povos indígenas. Não havia texto. Durante trinta minutos se vivenciava um conjunto de cantos, danças e pantomimas. O ritmo lento das ações e os gestos ampliados, aliados às enormes máscaras e indumentárias transformavam os atores em estátuas vivas que envolviam os espectadores pela via sensorial.

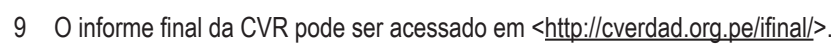


A saga de Canudos (2001), outro espetáculo de teatro de rua, fala sobre a luta pela terra e a necessidade da reforma agrária, nunca realizada de forma plena no Brasil. Recupera o caráter político do movimento liderado por Antônio Conselheiro no final do século dezenove, que comumente é retratado como um louco e fanático religioso. Ao coletivizar a terra e o trabalho, os camponeses desafiaram os latifundiários, o governo e a igreja. No espetáculo a formação da cidade de Canudos é fruto da busca por uma sociedade mais justa e igualitária. Mostra a resistência dos sertanejos, que derrotaram o exército várias vezes, até serem barbaramente dizimados.

É importante salientar que os Yuyas, assim como o Ói Nóis, dialogam desde o seu surgimento com movimentos sociais locais que lutam pelos direitos humanos e justiça social, assim como movimentos que têm reivindicações próprias de cada país, como a questão da reforma agrária no Brasil. A saga de Canudos, por exemplo, foi um espetáculo concebido em homenagem ao MST (Movimento dos Trabalhadores Rurais Sem Terra), movimento social que luta pela reforma agrária e que ganhou grande expressividade após o período de redemocratização no Brasil. O Ói Nóis Aqui Traveiz é parceiro do MST desde o princípio do movimento: no dia 1ำ de maio de 1986, dia do trabalhador, quando houve uma grande marcha que saiu da Fazenda Annoni em direção à capital do Rio Grande do Sul, na ocasião da chegada dos colonos sem-terra em Porto Alegre, o Ói Nóis apresentou Teon - morte em tupi-guarani para mais de 2.000 pessoas. Símbolo de resistência do MST e da luta pela terra, a ocupação da Fazenda Annoni ocorreu em 29 de outubro de 1985 por mais de 7.000 trabalhadores rurais sem-terra, e foi a primeira realizada por famílias organizadas no MST, que já vinham se estruturando desde o acampamento Encruzilhada Natalino, também na região norte do estado do Rio Grande do Sul.

A partir daí o MST se consolida como movimento e suas práticas se disseminam por todo o território nacional, transformando-se num dos maiores movimentos sociais da América Latina. Desde então, o Ói Nóis manteve um intenso diálogo que levou o grupo a realizar apresentações de diversos espetáculos de teatro de rua em acampamentos e assentamentos rurais. Também realizou entre 2006 e 2007 uma oficina teatral de longa duração no Assentamento Sepé Tiaraju, em Águas Claras, no município de Viamão. A oficina, realizada em parceria com o grupo Peça pro Povo, ajudou a fortalecer o uso do teatro como instrumento de reflexão sobre a própria realidade dos acampados e assentados. Na oficina foi realizado o exercício cênico Ayuka Karaiba (Morte aos brancos), apresentado no V Congresso Nacional do MST, que aconteceu em Brasília em junho de 2007. O exercício cênico trazia a história das Missões Jesuíticas, marcando os 250 anos de morte de Sepé Tiaraju e reivindicando a história desse líder indígena que dá nome ao assentamento e ao seu centro de formação, Filhos de Sepé, onde aconteceu o processo de criação. A luta de Sepé Tiaraju $^{10}$ e do Povo Guarani foi uma luta em defesa da soberania dos indígenas sobre a

10 Sepé Tiaraju foi um líder indígena dos Sete Povos das Missões Orientais do Uruguai (território hoje integrado ao estado do Rio Grande do Sul) que virou herói para seu povo. Em 1750, Portugal e Espanha assinaram o Tratado de Madri, pelo qual Portugal cederia a Colônia do Sacramento (fundada pelos portugueses onde hoje é o Uruguai) à Espanha em troca da região dos Sete Povos. Para concretizar o acordo, os povos guaranis deveriam abandonar as sete aldeias da margem oriental do rio Uruguai. Os indígenas não aceitaram o tratado e pegaram em armas para defender suas terras, dando início a Guerra Guaranítica, contra tropas espanholas e portuguesas. Os guaranis inicialmente tiveram muitas vitórias, mas em fevereiro de 1756, após uma série de derrotas, cerca de 1.500 guaranis foram dizimados na batalha de Caiboaté (nas proximidades da cidade gaúcha de São Gabriel). Sepé Tiaraju morreu em combate e tornou-se herói popular. Sua resistência foi sintetizada numa frase que ele teria pronunciado: "Esta terra tem dono!". 
terra e contra o genocídio praticado pelos impérios de Portugal e Espanha. Com esse trabalho, os assentados podiam refletir sobre sua própria luta contra o latifúndio e o agronegócio exclusivista e predador.

Essa oficina realizada no assentamento rural, entre 2006 e 2007, em parceria com o MST, fazia parte da ação Teatro como instrumento de discussão social. Consiste na realização de oficinas teatrais com jovens e adultos de bairros populares da região metropolitana de Porto Alegre, com o objetivo de formar núcleos culturais. As oficinas realizadas em bairros de periferia possibilitam a sensibilização e a experiência do fazer teatral para um grande número de pessoas que não teria acesso aos espaços culturais do centro da cidade. Essa ação, como seu nome indica, aposta que o teatro pode tornar-se um instrumento de indagação e conhecimento de si mesmo e do mundo, ao questionar os mecanismos que perpetuam os preconceitos e naturalizam as desigualdades sociais. Propõem-se exercícios em que o corpo seja utilizado de forma diferente da utilizada no cotidiano, provocando novas formas de se expressar. Isso faz surgir nos oficinandos a necessidade de redefinir seu lugar e seu papel como indivíduo na sociedade, redescobrindo sua cidadania.

A ação, surgida em 1988, veio da vontade de levar para a periferia a prática de oficinas teatrais, que já aconteciam na sede do grupo. As apresentações de espetáculos de teatro de rua em bairros de periferia de Porto Alegre aproximaram o Ói Nóis de diversas comunidades. Junto à primeira gestão do PT (Partido dos Trabalhadores) na Prefeitura Municipal de Porto Alegre, essas comunidades foram parceiras na implementação de oficinas populares de teatro, que deram origem ao Projeto Descentralização da Cultura no município de Porto Alegre. Embora essas oficinas tenham o teatro como prática principal, elas se desdobram em outras práticas culturais e sociais que são importantes na comunidade. No Bairro Restinga, por exemplo, algumas pessoas que fizeram as primeiras oficinas criaram uma rádio comunitária.

A necessidade de questionar os padrões sociais vigentes entre pessoas de uma mesma comunidade também levou o Grupo Cultural Yuyachkani a desenvolver diversos trabalhos em parceria com movimentos sociais. Em 1988 o Movimento Negro Francisco Congo, sabendo que o grupo trabalha e investiga as máscaras das danças peruanas e sua poética no teatro, pede que investigue as máscaras do Son de los Diablos. Segundo Ana Correa (apud Escobar, 2015), a origem do Son de los Diablos está no período de evangelização, em que os espanhóis buscavam extirpar as crenças e a cosmovisão dos indígenas e negros, sob o argumento de acabar com as idolatrias. No processo de evangelização se utilizava o teatro, como o auto sacramental, uma espécie de procissão com anjos e demônios, sendo que os demônios eram sempre representados por negros. Essa dança fazia parte da celebração do Corpus Christi. As confrarias de negros tomaram isso como uma possibilidade de resistência cultural para introduzir sua música e suas danças, trazidas da África e misturadas à cultura peruana. Com o tempo a dança saiu da celebração de Corpus Christi para fazer parte do carnaval nas ruas onde residem os afro-peruanos. A dança desapareceu das ruas de Lima na década de 1940. Nos anos 1970, Victoria Santa Cruz, diretora do Instituto Nacional do Folclore, retoma e encena novamente o Son de los Diablos. O Movimento Negro Francisco Congo, por sua vez, leva a tradição de volta para as ruas, como parte do carnaval. 
Sobre essa experiência, a atriz Ana Correa conta que fizeram as máscaras tomando como base o molde dos rostos e a fisionomia dos afro-peruanos, agregando o elemento dos chifres. Enquanto investigavam as máscaras, as pessoas do movimento viram que o Yuyachakani tinha um espaço para ensaiar e pediram para ensaiar lá. No fim, todo o grupo terminou dançando com o Movimento Negro Francisco Congo e levando o carnaval às ruas.

Em 2004, diversas instituições, incluindo o Yuyachkani, decidiram celebrar o primeiro grande carnaval negro em Rímac, comemorando os 150 anos da abolição da escravidão no Peru. No ano seguinte, o Yuyachkani introduziu o carnaval negro no recém criado Festival Magdalenarte, com o apoio da Municipalidade de Magdalena del Mar. Desde então o Carnaval Negro se apresenta na Praça Tupac Amaru no último sábado de março. Fidel Melquiades Carvallo, também integrante do Yuyachkani, que impulsionou o Son de los Diablos e que tinha ancestrais afro-peruanos, faleceu em 2012. Como uma homenagem à sua trajetória o carnaval passou a se chamar Carnaval Negro Fidel Melquiades.

Esse exemplo, no qual o grupo Yuyachkani fez parte da recriação de uma dança perdida, que exaltava a resistência cultural dos descendentes afro-peruanos, nos mostra a capacidade de articulação do grupo com movimentos sociais e como isso pode ser potente para a (re)criação de novas tradições culturais, que desafiam o pensamento hegemônico e dão protagonismo a setores sociais marginalizados. Levar o som dos diabos todos os anos para as ruas de Magdalena del Mar é um ato de diversão e subversão.

Uma ação pedagógica e ao mesmo tempo ativista importante na trajetória do grupo foram as oficinas para crianças e jovens de Guayabo, durante cinco anos consecutivos (1994-1998). O grupo convocou artistas independentes, músicos, atores e dançarinos que tivessem interesse em fazer um trabalho com as crianças e os jovens da pequena comunidade afro-peruana de Guayabo, que fica no distrito de El Carmen, no departamento de Ica, localizada aproximadamente a duzentos quilômetros ao sul de Lima e que possuía em torno de cem casas.

Ana Correa (2014) recorda que quando chegaram em Guayabo, já queriam trabalhar a identidade afro-peruana. Descobrir que as crianças desse povoado chamavam umas às outras, para insultar-se, de africanos, reforçou no Yuyachkani a vontade de, por meio da arte, trabalhar o sentido de identidade, pertencimento e ancestralidade. Nessas oficinas, pouco a pouco, conseguiram integrar as mães e os jovens do povoado.

Lena Bjerregaard, pesquisadora que participou da quarta edição do projeto, em 1997, descreve algumas dessas oficinas. Elas foram divididas por faixas etárias e envolveram a criação de bonecos ou fantoches de diversos materiais, mais ou menos elaborados, dependendo da faixa etária. Cada oficina possuía uma ou mais canções próprias, que foram ensinadas pelos oficineiros. A partir das canções e dos bonecos, os oficinandos contavam histórias e lendas que foram apresentadas numa noite de festa no povoado. Sobre o projeto, a pesquisadora afirma que essa experiência pedagógica 
se basó en recordarle a esa comunidad negra su origen africano, que no sólo fue la esclavitud, sino que ellos provenían de un continente poseedor de una gran riqueza cultural y material que les es propia genéticamente y que por ello los hace tan diferentes de otras comunidades del Perú. Recordarse no con nostalgia sino con orgullo y dignidad. Mirar su raíz para recuperar sus valores y de nuevo expresarse creativamente. (Bjerregaard, 1999, n.p.)

Para seu trabalho artístico e pedagógico, o grupo Yuyachkani toma como referência duas fontes distintas: por um lado os ritos, o sagrado e o espaço andino; por outro, a herança de uma teatralidade universal tanto do oriente como do ocidente. Segundo Fernando Mencarelli, aparentemente, o Yuyachkani nos propõe um paradoxo:

a busca por um corpo descolonizado através da aprendizagem de técnicas e práticas corporais estrangeiras. A procura por experienciar uma outra forma de ser do corpo, um corpo outro que permita perceber os condicionamentos e limites do próprio corpo imerso em seus padrões culturais. $(2013$, p. 2)

Para encontrar um corpo que rompa com os condicionamentos e padrões culturais, o grupo investiga o comportamento cênico tanto a partir de técnicas populares do Peru, como de outras fontes ocidentais e orientais. Esse duplo movimento assume que o teatro é uma construção cultural, que pertence a um determinado tempo e espaço, e que se transforma ao longo do tempo em busca de novas fronteiras. Segundo Mencarelli (2013, p. 5), o Yuyachkani

vai buscar muitas culturas para encontrar seus corpos. Por isso, para ele, a cultura do ator é composta de múltiplos saberes. Porque a identidade é algo relativo, porque afirmar identidade é criar cultura no presente. Para ele, o ator tem que ter muitas culturas corporais. Não para usá-las, mas porque elas lhes dão princípios.

Em suas diversas oficinas, o Ói Nóis também busca aquilo que chama de descolonização do corpo. Se nossos corpos cotidianos muitas vezes refletem atitudes, ideias e formas preestabelecidas - aprendidas por meio de uma educação que visa a domesticação, naturalizando a diferença colonial e hierarquizando saberes - o fazer teatral busca romper com os automatismos. O trabalho com ações físicas não cotidianas, por exemplo, procura desfazer esses automatismos em busca de um gesto significativo, que ultrapasse a mimesis e o naturalismo da vida cotidiana. Como afirma Beatriz Britto (2008, p. 80),

os exercícios utilizados, dentre eles, a criação de sequências individuais de ações, visam desenvolver primeiramente a presença cênica ${ }^{11}$ e a organicidade da atuação, cuja primeira condição é romper com hábitos e condicionamentos que travam a espontaneidade e a natureza profunda do ator.

O gesto decolonial, portanto, consiste para os dois grupos em pedagogias que permitem subverter hábitos e condicionamentos culturais. Ao invés de repetir o já estabelecido, busca-se criar com autonomia, sem hierarquizar princípios, técnicas e saberes.

11 A autora faz referência ao conceito de "presença cênica". Para maiores informações pode-se consultar Silva (2017), Duenha e Nunes (2017), Nunes e Baumgartel (2015). 


\section{Gestos e pedagogias do teatro decoloniais}

Os grupos Yuyachkani e Ói Nóis Aqui Traveiz, ao assumirem seu lugar próprio de enunciação, encontram novas perspectivas de produção de saber, que cruzam práticas e histórias locais a práticas e histórias estrangeiras, valorizando a sua capacidade de articular o pensamento, de compreender o mundo a partir do próprio mundo em que vivemos. A autonomia que os grupos têm ao tomar para si os princípios que melhor lhes permitem criar uma cultura própria e singular evidencia a independência e a potência do local e do emergente frente aos imperativos universalizantes e hierárquicos. A prática artística e pedagógica desses grupos resiste à colonialidade do poder e do saber, uma vez que descentraliza e democratiza saberes. A reflexão de Ana Correa sobre a relação do Yuyachkani com o ativismo cultural evidencia a necessidade do grupo em produzir formas próprias de conhecimento e comunicação desenvolvidas num contexto local:

\footnotetext{
Yuyachkani ha participado en la creación de obras dirigidas y relacionados con la sociedad y la diversidad cultural peruana buscando involucrar en un acto reflexivo y apasionante al espectador. Nos interesa mostrar la gran diversidad peruana, y buscamos inspiración tomando como referencia los ritos, lo sagrado, el espacio andino, entre otros, para provocar una introspección en el pasado que nos haga entender el presente. La misión de Yuyachkani es estimular el desarrollo de las artes escénicas como un espacio de creación, de invención, que permita cambiar y transitar por los lenguajes más diversos para desarrollar formas genuinas de teatralidad nacidas de la necesidad de comunicar en un contexto propio. (Correa, 2014, p. 60)
}

Essa liberdade na construção do conhecimento aponta novas possibilidades de se pensar, atuar, criar, existir. Esse outro-modo ou modo-outro de vida está nas fronteiras, nas margens, nas bordas, aliado à ideia de pensamento liminar proposta por Mignolo. É um processo que convida a intervir de forma diferente no mundo e criar novas formas de existência a partir de seus próprios afetos, de seus próprios corpos, de suas próprias ações, de suas próprias vozes.

Isso sem esquecer de aliar-se a outros coletivos culturais, políticos e sociais, pois é impossível compreender a realidade e atuar em suas estruturas sozinho. Reconhecer o conhecimento produzido por outros movimentos (feminista, negro, indígena, sem-terra, sem-teto, de luta por memória, por ações afirmativas, etc.) é fundamental para cruzar as fronteiras fictícias de exclusão e marginalização que limitam e impõem barreiras em nosso conhecer e reconhecer-se, para então tomar novas posturas e novas perspectivas carregadas de sentimento e intenção decolonial. Segundo Catherine Walsh, o capitalismo foi e segue sendo "el corazón de una matriz colonial que pretende controlar, definir y dominar a partir de un marco eurocéntrico y occidental las identidades sociales" (apud Richard, 2010, p. 101), assim como o conhecimento, a subjetividade, a natureza, a espiritualidade e a cultura. O esforço desses grupos teatrais em desafiar essa matriz colonial de dominação, em existir apesar dessa matriz, em seu próprio interior e com suas contradições, constitui-se num gesto decolonial.

As práticas pedagógicas desses grupos nos ensinam que, mais que romper com a ordem dominante, a matriz colonial e seus princípios universais e hierarquizantes, é 
preciso criar e construir outras formas de ser e de se pensar sobre o mundo, de forma relacional e não individual. Walsh chama esses tipos de práticas de insurgentes, que "trabajan fuera, en los bordes y los márgenes, así como adentro, abriendo y ensanchando las grietas y fisuras decoloniales" (2014, n.p.). Essas fissuras denotam aberturas ou princípios, que podem até debilitar ou fraturar o todo hegemônico. Seu efeito depende do que acontece nessas fissuras, de como se plantam as sementes, como elas brotam, florescem e crescem, e de como elas estendem ainda mais as rupturas e aberturas. É claro que as rachaduras também podem ser preenchidas e recobertas, fazendo parecer menos evidentes as rupturas, como se tivessem desaparecido. Mas as rachaduras, assim como os espaços pedagógicos que buscam romper com a matriz colonial, podem ser lugares de insurgência.

Se pensarmos nos exemplos pedagógicos trazidos aqui, percebemos que a insurgência não se dá apenas num plano político, mas também nos âmbitos epistêmicos e existenciais. O gesto decolonial, que desafia a matriz colonial, ensina novos saberes e novas possibilidades de existência. Numa oficina teatral, jovens assentados do Rio Grande do Sul puderam refletir de forma criativa e lúdica sobre o direito à terra e a sua própria luta diária por dignidade e justiça social, a partir da figura emblemática do líder guarani Sepé Tiaraju. Em outras oficinas, num pequeno povoado afro-peruano, crianças que insultavam umas às outras usando o termo africano recordaram suas próprias origens africanas, dessa vez com dignidade, percebendo que possuem uma riqueza cultural que lhes é própria. A partir de uma oficina de máscaras, um grupo teatral alia-se a um movimento negro na recriação de uma manifestação cultural que leva para as ruas divertimento e reflexão, visibilizando uma parcela da população marginalizada e discriminada.

A ideia de resistência, como um gesto decolonial, implica uma (re)existência. Implica reconhecer a complexidade cultural em que estamos inseridos e romper com hábitos e condicionamentos próprios de uma sociedade que transforma diferenças em valores e hierarquias, e que rebaixa não apenas saberes e culturas, mas povos inteiros e regiões do mundo. Implica em existir apesar da matriz colonial de dominação, criando espaços-rachaduras que propiciam novas formas de relacionar-se consigo e com os outros, que não se baseiam no individualismo e no pensamento hegemônico. Pelo contrário, são espaços que incentivam a autonomia e a liberdade de pensamento, em que se pode ser diferente do outro sem ser menos. São lugares em que se aprende a dialogar, pensar, criar com o outro, para inventar outro-modo ou modo-outro de existir. 


\section{Referências}

ALENCAR, Sandra. Atuadores da Paixão. Porto Alegre: Fumproarte, 1997.

BISIAUX, Lîlâ. Déplacement Épistémico-Esthétique du Théâtre Décolonial. Revista Brasileira de Estudos da Presença, Porto Alegre, v. 8, n. 4, p. 644-664, dez. 2018. Disponível em: http://dx.doi.org/10.1590/2237-266078793. Acessado em: 07 ago. 2019.

BJERREGAARD, Lena. Memorias del Guayabo: documentos de teatro $n^{\circ} 5$. Lima: Grupo Cultural Yuyachkani, 1999.

BRITTO, Beatriz. Uma tribo nômade: a ação do Ói Nóis Aqui Traveiz como espaço de resistência. Porto Alegre: Ói Nóis na Memória, 2008.

CORREA, Ana. Grupo Cultural Yuyachkani. In: OLIVOS, Fernando; SALAZAR, Ximena (org). Artivismo: cambio social y activismo cultural. Lima: Universidad Peruana Cayetano Heredia, 2014, p. 54-62.

DUENHA, Milene Lopes; NUNES, Sandra Meyer. Presença que não se Faz Só: potências de afeto no ato de com-por entre corpos. Revista Brasileira de Estudos da Presença, Porto Alegre, v. 7, n. 1, p. 99-122, Apr. 2017. Disponível em: http://dx.doi. org/10.1590/2237-266063628. Acessado em: 07 Aug. 2019.

ESCOBAR, Laura. Ana Correa: El arte es un camino de sanación para una sociedad. TVRobles, mar. 2015. Disponível em: https://tvrobles.lamula.pe/2015/03/27/ana-correa-el-arte-es-un-camino-de-sanacion-para-una-sociedad/tvrobles/ Acesso em: 21 fev. 2017.

FOUCAULT, Michel. Em defesa da sociedade: curso no Collège de France (1975-1976). São Paulo: Martins Fontes, 1999.

ICLE, Gilberto. Estudos da Presença: prolegômenos para a pesquisa das Práticas performativas. Revista Brasileira de Estudos da Presença, Porto Alegre, v. 1, p. 9-27, 2011. Disponível em http://dx.doi.org/10.1590/2237-266023682 Acesso em: 20 jan. 2019.

MENCARELLI, Fernando Antonio. Práticas corporais e alteridade na cultura de grupo: Yuyachkani e Workcenter. Dez. 2013. Disponível em: http://pt.slideshare.net/fernandomencarelli/prticas-corporais Acesso em: 22 jul. 2016.

MIGNOLO, Walter. Decolonialidade como o caminho para a cooperação. Revista do Instituto Humanitas Unisinos, n. 431, nov. 2013. Disponível em: http://www.ihuonline.unisinos.br/index.php?option $=$ com_content\&view $=$ article\&id $=52538$ secao $=431$ Acesso em 22 jul. 2016. 
MIGNOLO, Walter. Histórias locais, projetos globais: colonialidade, saberes subalternos e pensamento liminar. Belo Horizonte: Editora UFMG, 2003.

MIGNOLO, Walter. Looking for the Meaning of "Decolonial Gesture". E-misférica, vol. 11, n.1, 2014. Disponível em: http://hemisphericinstitute.org/hemi/en/emisferica-111-decolonial-gesture/mignolo Acesso em: 22 jul. 2016.

NUNES, Juarez; BAUMGARTEL, Stephan. A Construção de Presença e a Cena Teatral Multimidiática: a hegemonia de uma presença imanente. Revista Brasileira de Estudos da Presença, Porto Alegre, v. 5, n. 3, p. 640-661, Dec. 2015. Disponível em: http://dx. doi.org/10.1590/2237-266047774. Acessado em: 07 Aug. 2019.

RICHARD, Nelly. En torno a los estudios culturales: localidades, trayectorias y disputas. Santiago de Chile: Editorial ARCIS, 2010.

SCHECHNER, Richard. Ritual (do Introduction to Performance Studies). In: LIGIÉRO, Zeca. Performance e Antropologia de Richard Schechner. Rio de Janeiro: Mauad X, 2012, p. 49-90.

SILVA, Wellington Amâncio da. Hans Ulrich Gumbrecht Leitor de Martin Heidegger: concepção de produção de presença. Revista Brasileira de Estudos da Presença, Porto Alegre, v. 7, n. 3, p. 505-522, dez. 2017. Disponível em: http://dx.doi.org/10.1590/2237266069414. Acessado em: 07 ago. 2019.

TAYLOR, Diana. O arquivo e o repertório: performance e memória cultural nas Américas. Belo Horizonte: Editora UFMG, 2013.

WALSH, Catherine. Notas pedagógicas desde las grietas decoloniales. E-misférica, vol. 11, n.1, 2014. Disponível em: http://hemisphericinstitute.org/hemi/es/e-misferica-111-gesto-decolonial/walsh. Acesso em: 22 jul. 2016.

Recebido em: 24/02/2019 Aprovado em: 05/08/2019 